\title{
Middle Cerebral Artery Aneurysm Coiling without Assisted Techniques - A Good Alternative, Single Venture Experience
}

\author{
UMAIR RASHID CH, SAIMA AHMED, SOHAIL AKHTAR \\ ABU BAKAR SIDDIQUE, AMIR AZIZ, SOBIA ISMAIL \\ Punjab Institute of Neurosciences (PINS), Lahore General Hospital, Lahore - Pakistan
}

DOI: $10.36552 /$ pjns.v24i3.471

\begin{abstract}
Objective: To evaluate the result of a coiling of middle cerebral artery aneurysms without auxiliary techniques.

Material and Methods: This study was conducted from June 2010 to September 2019 in the Department of Neuroradiology, Punjab Institute of Neurosciences, Lahore. There were a total of 500 patients with unilateral and bilateral cerebral aneurysms at the MCA level that have been included in this study which comprise of both sexes.

Results: There was a total of 500 patients, which comprised of 200 (40\%) men and 300 (60\%) women. Their ages ranged from 22 to 65 years. The majority number of patients was in their fifth $180(30 \%)$ and sixth decade 150 (30\%) of life. In our study, a successful coiling was performed in 490 (98\%) patients with minimal recanalization of MCA aneurysms. In 10 (2\%) procedure was unsuccessful due to vasospasm.
\end{abstract}

Conclusion: The conventional coiling in middle cerebral artery aneurysms can be effective and safe without auxiliary techniques.

Keywords: Cerebral aneurysm, endovascular coiling, Middle Cerebral Artery.

\section{INTRODUCTION}

The goal of treating an un-ruptured aneurysm is to prevent the aneurysm from rupturing, while ruptured intracranial aneurysms are intended to prevent further bleeding. Several technical approaches can be chosen adapted to the specific anatomy, from "simple" coiling (conventional) to very composite stent or balloon assisted coiling: multi-catheter technique or Flow Diverter (FD). These "assisted techniques" are not only more difficult and have higher risk, but are very expensive too; the cost represents a serious managerial difficulty. Moreover, MCA aneurysms pose a unique threat \& challenge due to location, peri aneurysmal architecture \&supply to eloquent and vital areas of the brain. In this article we have described our encounter in the endovascular treatment of MCA aneurysms based on "simple coiling". ${ }^{1-3}$.

\section{MATERIAL AND METHODS}

\section{Study Setting}

It is a retrospective study of five hundred patients, which were selected for conventional coiling treatments, i.e. without any assistant technique, from June 2010 to September 2019 at the Department of Neuro-Interventional Radiology, Punjab Institute of Neurosciences (PINS) Lahore General Hospital, Lahore.

\section{Inclusion Criteria}

All aneurysm were coiled with detachable (framing, filling and finishing) coils. Only aneurysms situated in middle cerebral artery are taken into account, even if the patient had several aneurysms in other intracranial arteries. 


\section{Exclusion Criteria}

Patients with mycotic or distal MCA aneurysms with Glasgow coma scale less than 8 were excluded from this study.

\section{Data Collection}

Clinically, patients were classified according to Hunt and Hess and WNFS grading (world federation of neurological surgeons sub arachnoid hemorrhage grading system). Adult patients of both genders with MCA aneurysms were selected. Informed written consent was obtained from each patient. Prior to coiling procedure, DynaCT $3 \mathrm{D}$ angiography was performed using AXIOM Artis (Siemens Medical Solutions, Erlangen, Germany) for detection and elaboration of Angio-architecture of aneurysms \& its topology and orientation. All information was recorded on Pre-designed Proforma.

\section{Clinical Management}

Nimodipine was given through continuous infusion throughout the procedure. Immediate Post procedural DSA was done to confirm the residual sac or complete obliteration. Following the procedure, all the patients were awake, alert and oriented in person, place and time. Patients were kept under observation for $12-24$ hours \& vital signs were monitored.

\section{RESULTS}

\section{Gender Distribution}

Out of 500 patients, there were 200 males $(40 \%)$ and $300(60 \%)$ female patients (Table 1$)$.

Table 1: Gender Distribution.

\begin{tabular}{|c|l|c|c|c|}
\hline S. No. & Sex & Number & Percentage & $\begin{array}{c}\text { Cumulative } \\
\text { Percentage }\end{array}$ \\
\hline 1. & Male & 200 & $40 \%$ & $40 \%$ \\
\hline 2. & Female & 300 & $60 \%$ & $100 \%$ \\
\hline
\end{tabular}

\section{Age Range}

Their ages ranged from $22-65$ years (Table 2).

Table 1: Age Range.

\begin{tabular}{|c|c|c|c|}
\hline Age & Number & Percentage & $\begin{array}{c}\text { Cumulative } \\
\text { Percentage }\end{array}$ \\
\hline $10-20$ & - & - & - \\
\hline $21-30$ & 35 & $7 \%$ & $7 \%$ \\
\hline $31-40$ & 100 & $20 \%$ & $27 \%$ \\
\hline $41-50$ & 180 & $36 \%$ & $63 \%$ \\
\hline $51-60$ & 150 & $30 \%$ & $93 \%$ \\
\hline$>$ than 60 & 35 & $7 \%$ & $100 \%$ \\
\hline
\end{tabular}
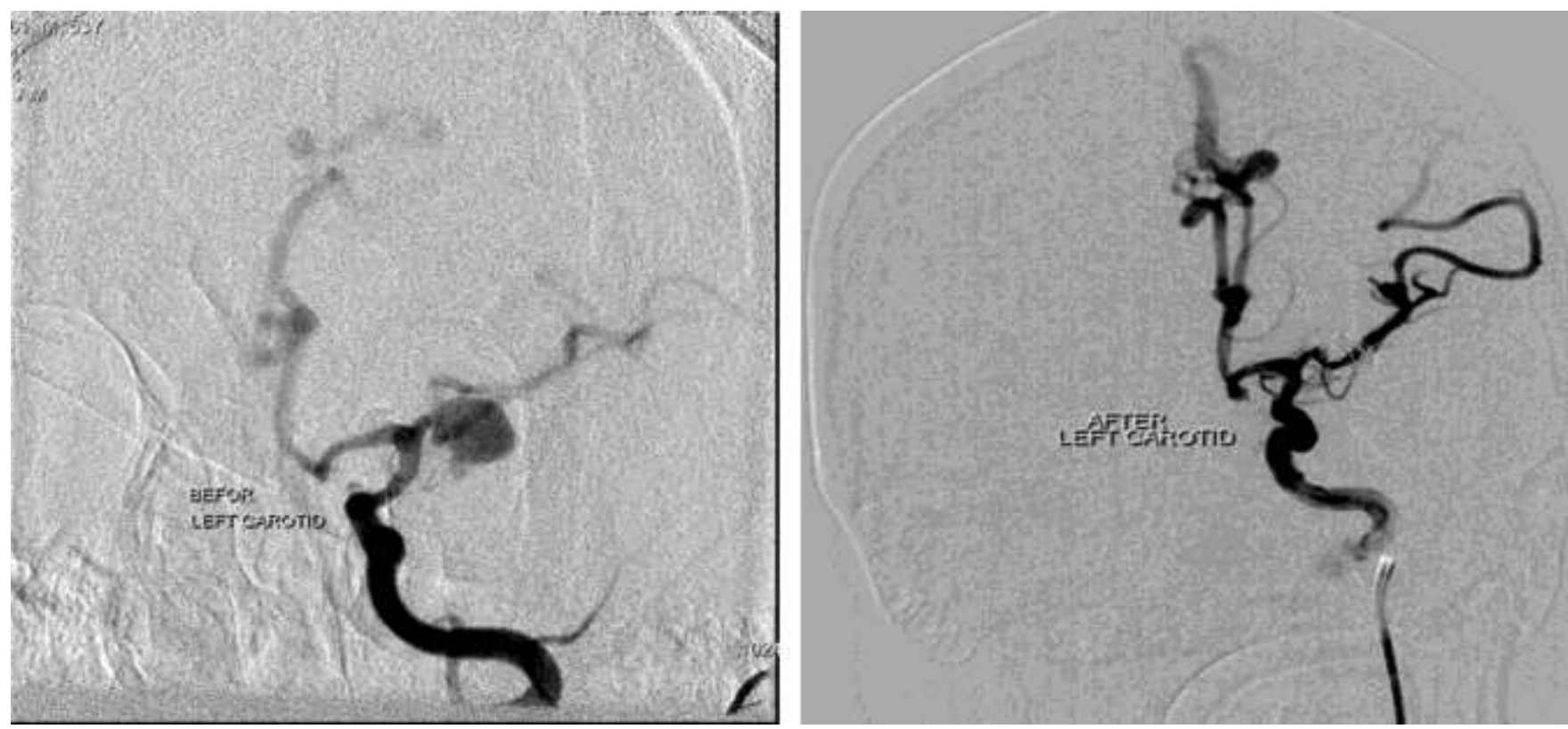

Fig. 1: Pre- and Post-Coiling Left MCA Bifurcation Aneurysm. 


\section{Outcome}

In our study effective coiling was achieved in all patients with less recanalization, none required repeat coiling at 6 month follow up MRI (Table 3).

Table 3: Clinical Presentation.

\begin{tabular}{|l|c|c|}
\hline Clinical Presentation & Number & Percentage \\
\hline Headache & 500 & $100 \%$ \\
\hline Vomiting & 500 & $100 \%$ \\
\hline
\end{tabular}

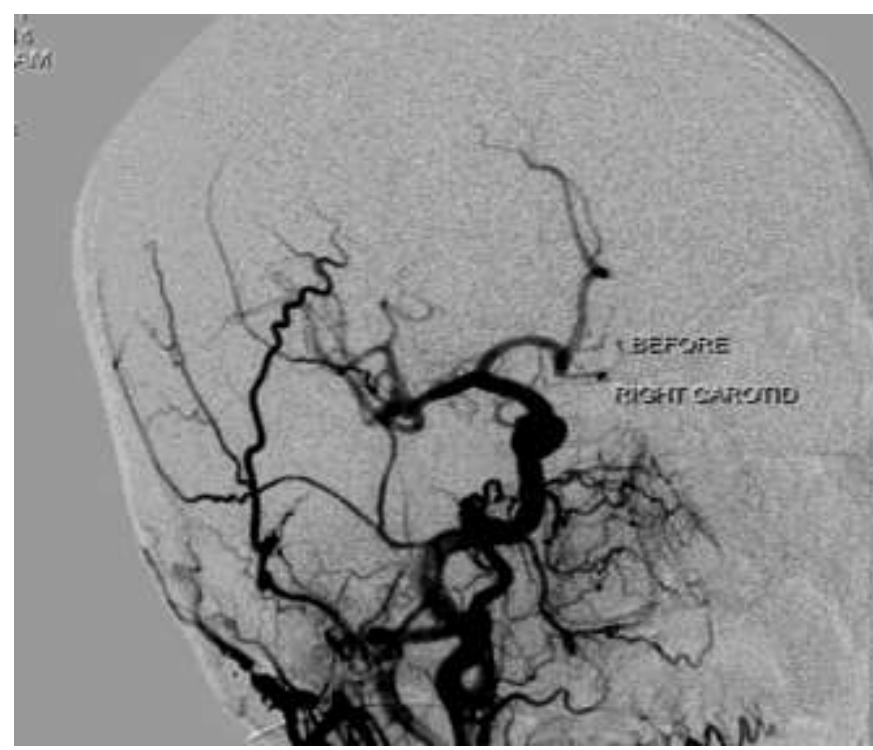

Fig. 2: Right MCA Bifurcation Aneurysm Pre-and Post-Coiling.
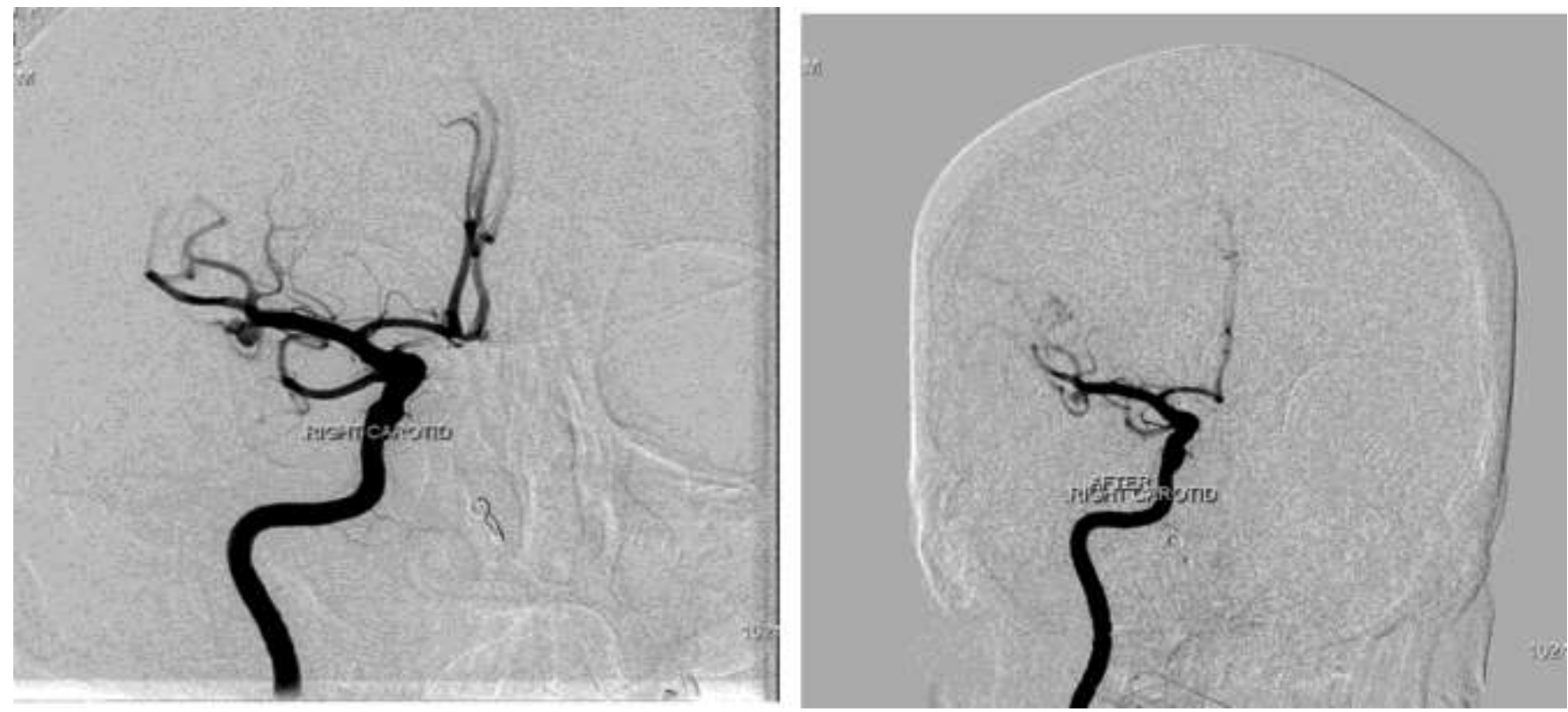

Fig. 3: Right MCA Bifurcation Aneurysm Pre- and Post-Coiling. 


\section{Clinical Presentation}

All patients with headache, vomiting, loss of consciousness in $50 \%$ cases. Neeb stiffness was present in $100 \%$ cases (Table 4 ).

Table 4: Procedure Success.

\begin{tabular}{|l|c|c|c|}
\hline $\begin{array}{l}\text { Clinical } \\
\text { Presentation }\end{array}$ & Number & Percentage & $\begin{array}{c}\text { Cumulative } \\
\text { Percentage }\end{array}$ \\
\hline Coilis Successful & 490 & $98 \%$ & $98 \%$ \\
\hline Coiling Failed & 10 & $2 \%$ & $100 \%$ \\
\hline
\end{tabular}
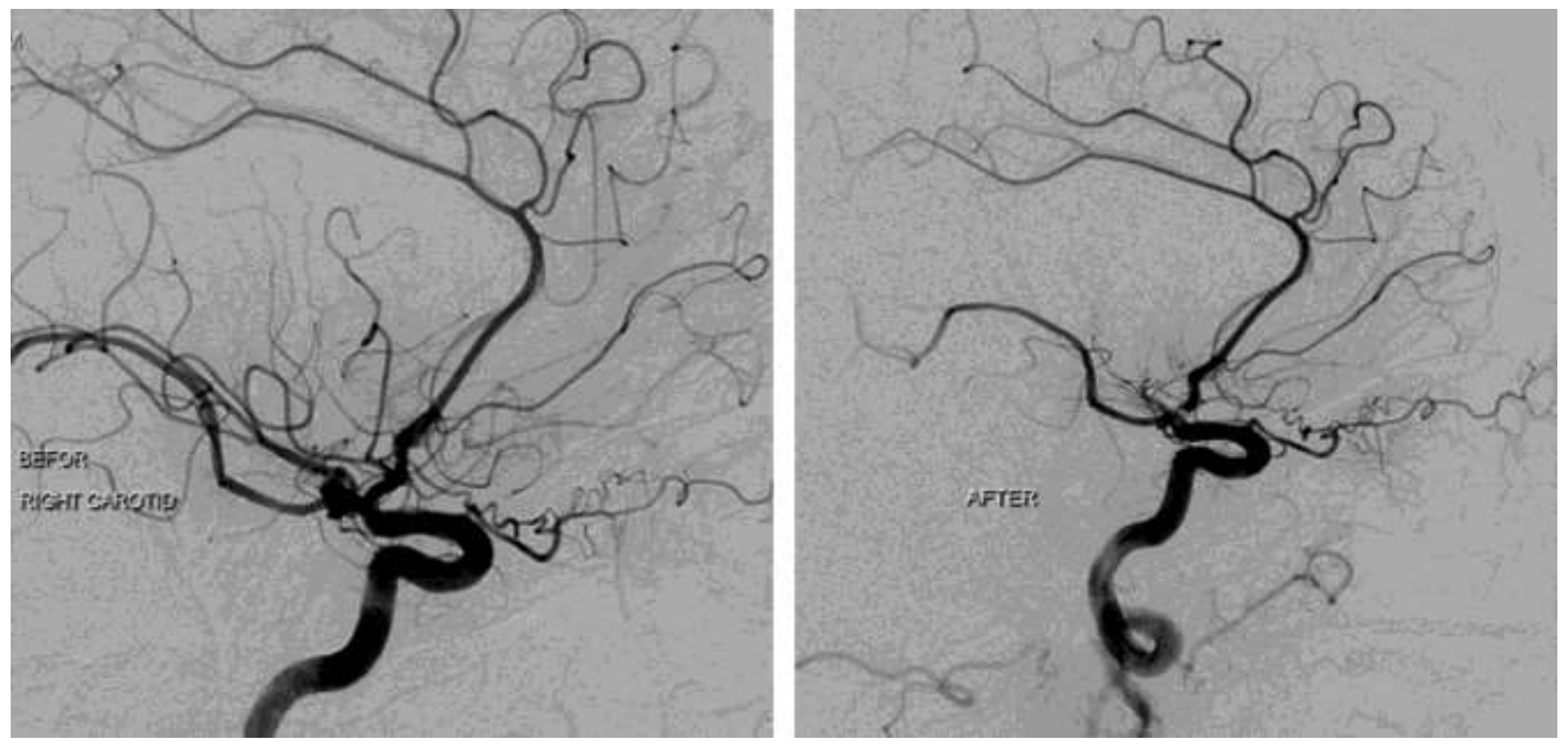

Fig. 4: Right MCA Bifurcation Aneurysm Pre- and Post-Coiling.
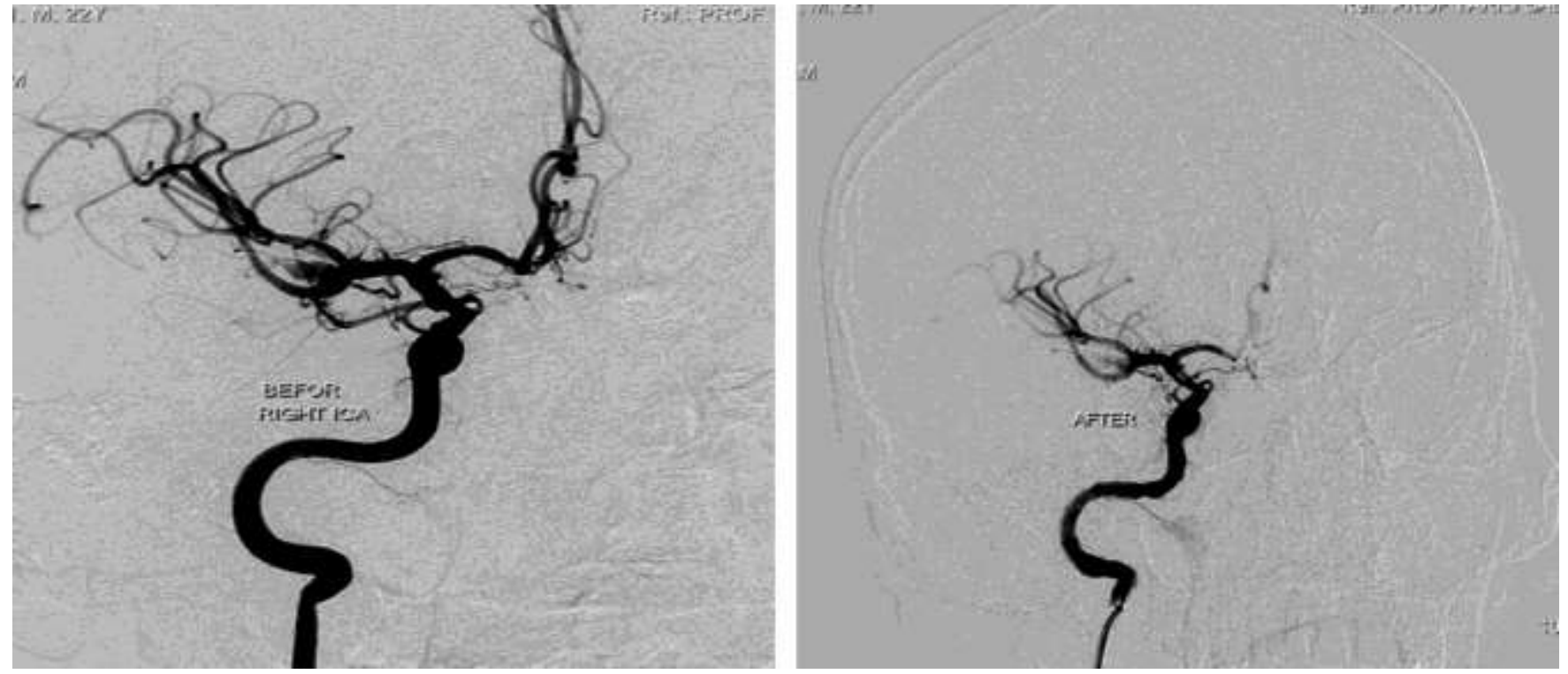

Fig. 5: Right MCA Bifurcation Aneurysm Pre- and Post-Coiling. 

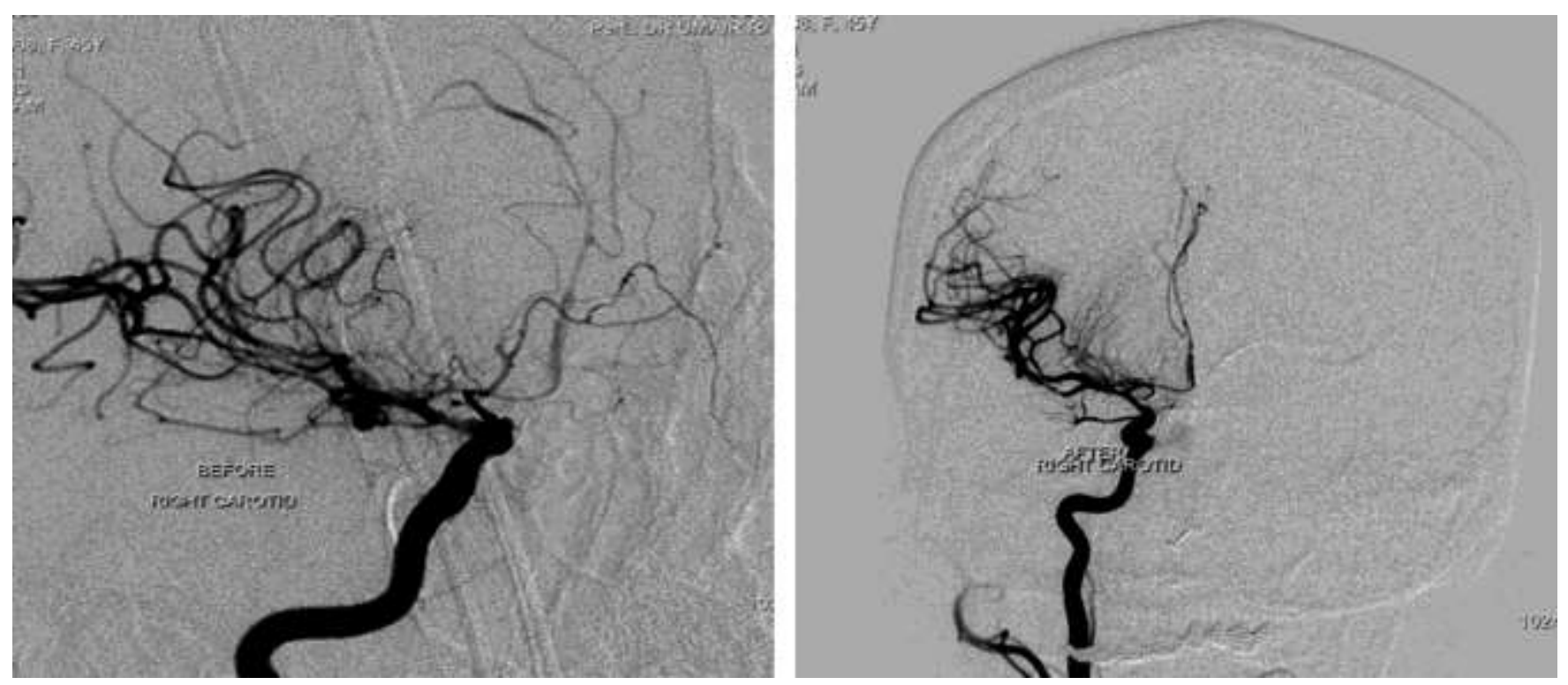

Fig. 6: Right MCA Bifurcation Aneurysm Pre- and Post-Coiling.

\section{Complications}

No significant complications like re bleed, stroke and death were observed in any case. Minor complications such as headache, visual field defects and vertigo were observed in $9 \%, 2 \%$ and $3 \%$ respectively. Intensive physiotherapy was required in $10 \%$ of the cases. In 10 ( $2 \%)$ patients the procedure was unsuccessful, due to a prolonged vasospasm phenomenon. These patients were referred to neurosurgery department (Table 5).
Table 5: Complication.

\begin{tabular}{|l|c|c|}
\hline Complication & Number & Percentage \\
\hline Headache & 45 & $9 \%$ \\
\hline Visual Field Defeat & 10 & $2 \%$ \\
\hline Vertigo & 15 & $3 \%$ \\
\hline Vasospasm & 10 & $2 \%$ \\
\hline Hemiparesis & 10 & $2 \%$ \\
\hline ICU Field Care & 50 & $10 \%$ \\
\hline
\end{tabular}
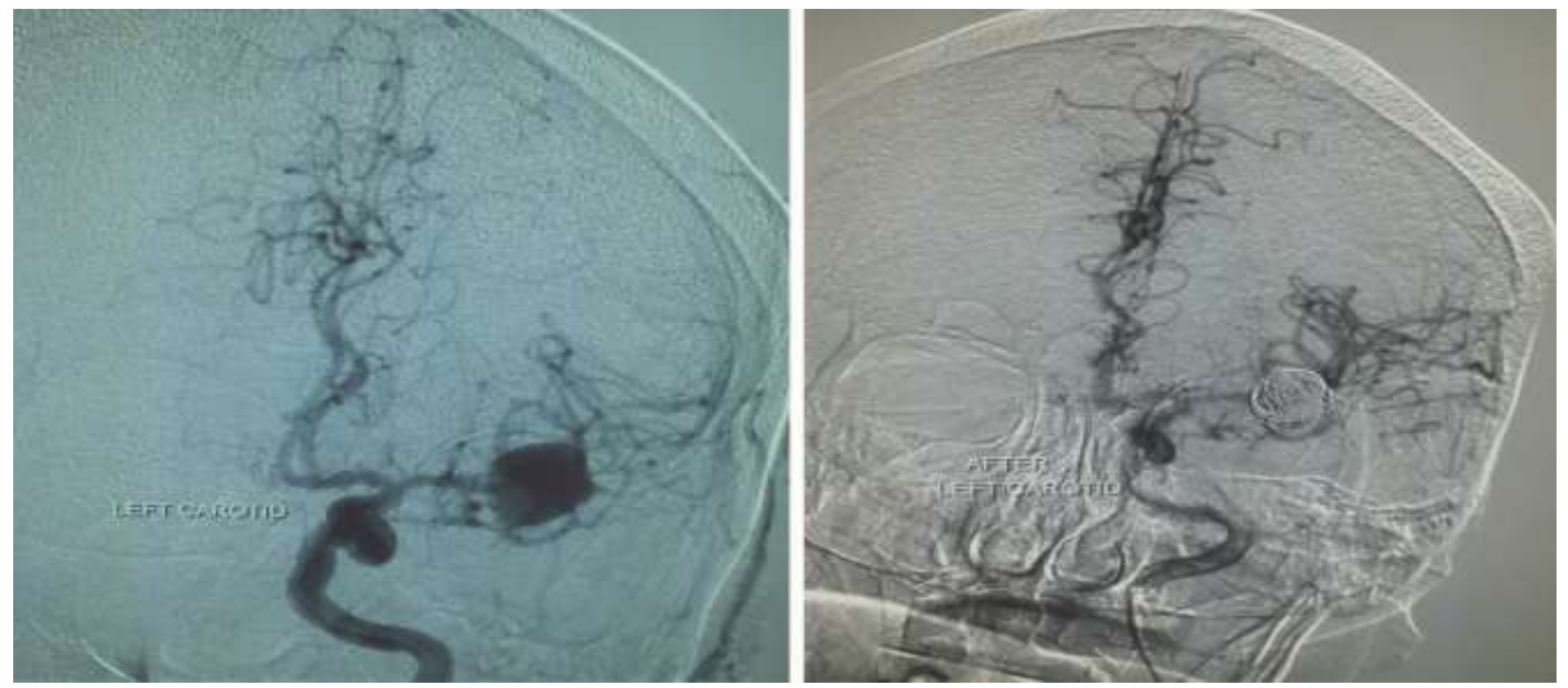

Fig. 7: Left MCA Bifurcation Aneurysm (Large) Pre-and Post-Coiling. 

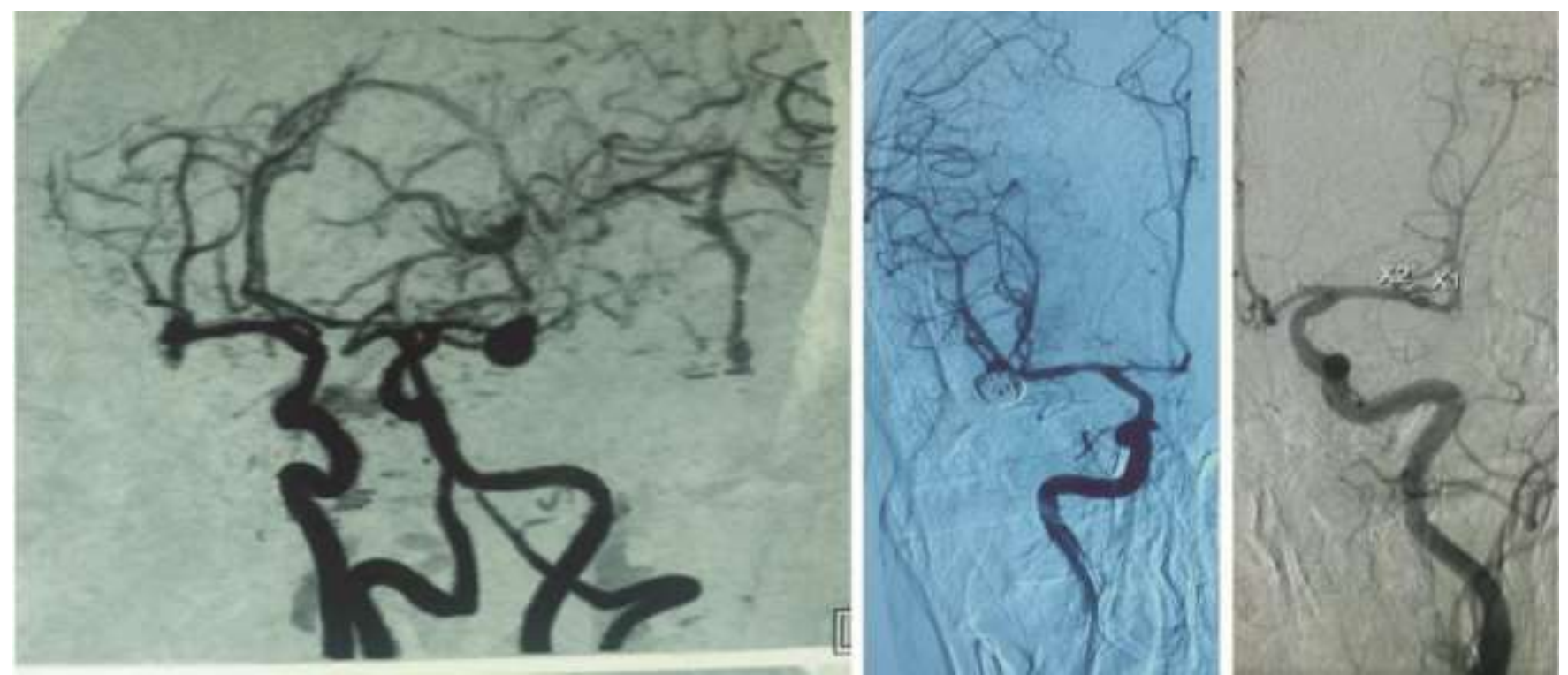

Fig. 8: Bilateral MCA Bifurcation Aneurysms Pre- and Post-Coiling.

\section{DISCUSSION}

In burst Middle cerebral artery aneurysms, subgroup analysis of ISAT in elderly patients (more than 65 years) disclosed mediocrity of coiling to clipping But for MCA aneurysms, which are un ruptured, coiling has been restricted, mostly due to the inimical aneurysm geometry (wide neck and/or incorporation of a branch into the neck). ${ }^{4-6}$ In the treatment of unruptured intracranial aneurysms, endovascular coiling has shown uniform and haughty results to clipping. ${ }^{7}$ Endovascular coiling of middle cerebral artery aneurysms has demonstrated higher procedure failure rate and less favorable results juxtaposed to the treatment of aneurysms at other locations ${ }^{8-9}$. MCA aneurysms, which show complex or non-geometrical shapes have a higher incidence of rupture rate. Perianeurysmal environment changes in size and shape because of acute ruptured aneurysms. ${ }^{10}$

Compartmentalization of basal cisterns, subarachnoid spaces such as arachnoid-Dural and Arachnoid-Pial influence the topology and orientation of aneurysms. This helps to avoid assisted techniques of coiling MCA. ${ }^{11-13}$ Along with other endovascular treatments, surgical clipping is still preferred choice for MCA aneurysms due to its composite anatomy and hoisted long-term reappearance rate of MCA aneurysms. ${ }^{14-15}$ Some authors favors surgical clipping over coiling techniques with less recurrent rates of ruptures \& complications. ${ }^{16,17}$ The presence of an intracerebral hematoma causing significant mass effect and requiring rapid evacuation contraindicates the endovascular approach. ${ }^{18,19,}{ }^{20}$ In our study coiling of MCA aneurysms, limited to cases with favorable anatomy, were performed successfully, except in ten patients who went in prolonged vasospasm, without any major complications and were shifted to neurosurgery for clipping. ${ }^{21-22}$

Accurate evaluation of anatomy of the aneurysm on $3 \mathrm{D}$ imaging and selection of patients may allow the endovascular treatment with the "simpler" conventional coiling approach.

\section{CONCLUSION}

Usual coiling in small to large MCA aneurysms in selected patients can be effectual and prudent, methodologically unostentatious than with assisted techniques.

\section{REFERENCES}

1. Hop JW, Rinkel GJ, Algra A, van Gijn J. Case-fatality rates and functional outcome after subarachnoid hemorrhage: a systematic review. Stroke, 1997; 28: 660-664.

2. Serbinenko FA. Catheterization, and occlusion of major cerebral vessels and prospects for the development of vascular neurosurgery. Vopr Neirokhir. 1971; 35: 1727.

3. Serbinenko FA. Balloon catheterization and occlusion of major cerebral vessels. J Neurosurg. 1974; 41: 125145. 
4. Guglielmi G, Vinuela F, Dion J, Duckwiler G. Electrothrombosis of saccular aneurysms via endovascular approach, part 2: preliminary clinical experience. J Neurosurg. 1991; 75: 8-14.

5. Guglielmi G, Vinuela F, Sepetka I, Macellari V. Electrothrombosis of saccular aneurysms via endovascular approach, part 1: electrochemical basis, technique, and experimental results. J Neurosurg. 1991; 75: $1-7$.

6. Johnston SC, Wilson CB, Halbach VV, Higashida RT, Dowd CF, McDermott MW, Applebury CB, Farley TL, Gress DR. Endovascular and surgical treatment of unruptured cerebral aneurysms: comparison of risks. Ann Neurol. 2000; 48: 11-19.

7. Johnston SC, Zhao S, Dudley RA, Berman MF, Gress DR. Treatment of unruptured cerebral aneurysms in California. Stroke, 2001; 32: 597-605.

8. Raftopoulos C, Mathurin P, Boscherini D, Billa RF, Van Boven M, Hantson P. Prospective analysis of aneurysm treatment in a series of 103 consecutive patients when endovascular embolization is considered the first option. J Neurosurg. 2000; 93: 175-182.

9. Mitchell P, Kerr R, Mendelow AD, Molyneux A. Could late rebleeding overturn the superiority of cranial aneurysm coil embolization over clip ligation seen in ISAT? Journal of Neurosurgery, 2008; 108: 437-442.

10. M; Spelle, L, Mounayer, C, Salles-Rezende, MT, Giansante-Abud, D, Vanzin-Santos, R, Moret. Intracranial aneurysms: treatment with bare platinum coils-aneurysm packing, complex coils, and angiographic recurrence, 2007; 243 (2): 500-8.

11. Raymond J, Guilbert F, Weill A, Georganos SA, Juravsky L, et al. Long-term angiographic recurrences after selective endovascular treatment of aneurysms with detachable coils. Stroke, 2003; 34 (6): 1398-1403.

12. Campi, A; Ramzi N, Molyneaux AJ, Summers, PE, Kerr, RS, Sneade, M, Yarnold, JA, Rischmiller, J, Byrne. Retreatment of ruptured cerebral aneurysms in patients randomized by coiling or clipping in the International Subarachnoid Aneurysm Trial (ISAT). Stroke, 2007; 38 (5): 1538-44.

13 J. M. vanDijk, R. J. Groen, M. terLaan, J. R. Jeltema, J.
J. Mooij and J. D. Metzemaekers. Surgical clipping as the preferred treatment for aneurysms of the middle cerebral artery. Acta, Neurochirurgica, 2011; 153: 2111-2117.

14. Molyneux AJ, Kerr RS, Birks J et al. Risk of recurrent subarachnoid haemorrhage, death, or dependence and standardized mortality ratios after clipping or coiling of an intracranial aneurysm in the International Subarachnoid Aneurysm Trial (ISAT): long-term follow-up. The Lancet Neurology. 2009; 8 (5): 427433.

15. Brinjikji W, Lanzino, Cloft GHL, Rabinstein A, Kallmes DF. Endovascular treatment of middle cerebral artery aneurysms: a systematic review and single-center series. Neurosurgery, 2011; 68 (2): 397-402.

16. Bulters DO, Santarius T, Chia HL, et al. Causes of neurological deficits following clipping of 200 consecutive ruptured aneurysms in patients with goodgrade aneurysmal subarachnoid haemorrhage. Acta Neurochirurgica. 2011; 153 (2): 295-303, 2011.

17. G“uresir E, Schuss P, Berkefeld J, Vatter H, Seifert V. Treatment results for complex middle cerebral artery aneurysms. A prospective single-center series. Acta Neurochirurgica. 2011; 153 (6): 1247-1252.

18. Morgan MK, Mahattanakul W, Davidson A, Reid J. Outcome for middle cerebral artery aneurysm surgery. Neurosurgery, 2010; 67(3): 755-761.

19. Nanda A, Vannemreddy PSS. Surgical management of unruptured aneurysms: prognostic indicators. Surgical Neurology, 2002; 58 (1): 13-20.

20. D. H. Park, S. H. Kang, J. B. Lee et al. Angiographic features, surgical management and outcomes of proximal middle cerebral artery aneurysms. Clinical Neurology and Neurosurgery, 2008; 110 (6): 544-551.

21. Vendrell JF, Menjot N, Costalat V, et al. Endovascular treatment of 174 middle cerebral artery aneurysms: clinical outcome and radiologic results at long-term follow-up. Radiology, 2009; 253 (1): 191-198.

22. Yang P, Liu J, Huang Q, et al. Endovascular treatment of wide neck middle cerebral artery aneurysms with stents: a review of16 cases. American Journal of Neuroradiology, 2010; 31 (5): 940-946.

\section{Additional Information}

Disclosures: Authors report no conflict of interest.

Ethical Review Board Approval: The study was conformed to the ethical review board requirements.

Human Subjects: Consent was obtained by all patients/participants in this study.

Conflicts of Interest:

In compliance with the ICMJE uniform disclosure form, all authors declare the following:

Financial Relationships: All authors have declared that they have no financial relationships at present or within the previous three years with any organizations that might have an interest in the submitted work.

Other Relationships: All authors have declared that there are no other relationships or activities that could appear to have influenced the submitted work. 


\section{AUTHORS CONTRIBUTIONS}

\begin{tabular}{|l|l|l|}
\hline Sr.\# & Author's Full Name & Intellectual Contribution to Paper in Terms of: \\
\hline 1. & Umair Rashid Ch. & Study design and methodology. \\
\hline 2. & Saima Ahmad & Paper writing, referencing, data calculations. \\
\hline 3. & Sohail Akhtar & Data collection and calculations. \\
\hline 4. & $\begin{array}{l}\text { Abu Bakar Siddique } \\
\text { Umair Rashid Ch }\end{array}$ & Analysis of data and interpretation of results etc. \\
\hline 5. & Amir Aziz & Literature review and manuscript writing. \\
\hline 6. & Umair Rashid Ch. & Analysis of data and quality insurer. \\
\hline 7. & Sobia Ismail & Proof reading. \\
\hline
\end{tabular}

Date of Submission: 01-05-2020

Date of Revision: 7-8-2020

Date of Online Publishing: 25-09-2020

Date of Print: 30-09-2020 